IMAFRONTE- $\mathrm{N}^{\mathrm{o}} 27.2020$, pp. 1-16

\title{
PRESUPUESTOS TERAPÉUTICOS Y PSEUDOMORFOSIS EN LOS TRABAJOS MARTYRS (2014) Y MARY (2016) DE BILL VIOLA
}

\author{
THERAPEUTIC FOUNDATIONS AND PSEUDOMORPHOSIS IN BILL \\ VIOLA'S WORKS MARTYS (2014) AND MARY (2016)
}

GUILLERMO AGUIRRE MARTÍNEZ

Universidad de Salamanca

\section{RESUMEN}

En 2014 Bill Viola completa su trabajo Martyrs, un encargo realizado por la Catedral de san Pablo, en Londres. Dos años después quedará concluida Mary, obra que complementa a Martyrs y que encuentra su ubicación, en esa misma catedral, en el extremo opuesto del ábside. Tomando como eje vertebrador la significación de los cuatro elementos (agua, tierra, aire, fuego) y el fenómeno de pseudomorfosis habitual en los trabajos de Viola, exploraremos los fundamentos de un arte terapéutico. La emergencia de contenidos profundos del imaginario permite la revitalización psicosomática del sujeto.

PALABRAS CLAVE: Bill Viola, Catedral de san Pablo, Videoarte, Arte contemporáneo.

\section{ABSTRACT}

In 2014 Bill Viola finished his work Martyrs, requested by Saint Paul's Cathedral, in London. Two years later the American artist ended another work, Mary, that complements Martyrs. Mary is located, also in Saint Paul's Cathedral, on the opposite side of the apse. Since the meaning of the four elements (water, earth, air and fire) and the idea of pseudomorphosis that normally structures Bill Viola's works, we will explore the premises of a therapeutic art. The emergence of deep sediments buried in our imaginary, allows the psychosomatic revitalisation of the individual.

KEY WORDS: Bill Viola, Saint Paul's Cathedral, Video Art, Contemporary Art. 


\section{LA TÉTRADA COMO ESTRUCTURA ORGANIZATIVA}

La recurrencia a tétradas asociables a los cuatro elementos clásicos -agua, tierra, aire, fuego-, o el empleo relativamente aislado -exento- de éstos como material de composición, resulta un lugar común en la trayectoria de Bill Viola hasta el punto de poder afirmarse que sobre esta organización se consolida su imaginario. Esta peculiaridad queda vinculada al hecho de que muchos de los personajes que protagonizan sus vídeos se ven sometidos a un proceso de ascesis ${ }^{1}$ llevado a cabo por medio de la interiorización y la simbólica interrelación, justamente, de agua, tierra, aire y fuego. A partir de la simbiosis de estos elementos el creador modela un objeto de propiedades y tendencias homeostáticas vinculadas a su deseo de conformar un arte terapéutico. ${ }^{2}$ Así, del mismo modo que los protagonistas de estos trabajos trascienden su particular naturaleza tras un áspero proceso purgativo, el espectador que contempla los vídeos podrá idealmente participar de una experiencia incidente en sus más hondas estructuras anímicas.

La obra Martyrs (2014), ubicada en la Catedral de san Pablo (Londres) y realizada, como de costumbre en Viola, con la colaboración de su mujer Kira Perov, participa de estas intenciones regeneradoras -terapéuticas- no desvinculadas de una función -si así pudiera hablarse- puramente estética. Es más, regresando a un concepto de arte ajeno al uso lúdico que hoy prevalece, es preciso comprender dichas cualidades como fundamentadoras de todo proceso y objeto estético, en la medida en que éste propone primeramente un desarrollo ascético que transforma potencialmente al individuo -tanto al creador como a quien se acerca a la obra-. Tampoco puede deslindarse la significación de este trabajo, como viene siendo repetido por Viola, de lo expresado en otra de sus composiciones, concretamente en Mary (2016), situada en el extremo opuesto del altar de san Pablo y con la que Martyrs conforma una unidad. Mary equilibra el contenido emocional del conjunto y hasta dota de significación al padecimiento de los mártires, según se encarga de recordar el artista estadounidense. ${ }^{3}$

\footnotetext{
${ }^{1}$ Antoni Gonzalo Carbó hace referencia a esta potencialidad de los trabajos de Viola. Con relación a una de sus realizaciones relativamente cercanas en el tiempo, señala: "En Surrender (Renuncia, 2001), el artista vuelve a tomar como referente la mística sufí, en concreto la idea de la rendición, la renuncia ascética o 'despojamiento' de sí mismo”' (2004: 57).

${ }^{2}$ Aspecto comentado, entre otros, por Yayo Aznar, quien tras aludir al vínculo en Viola de los cuatro colores primarios con "la felicidad, la tristeza, el enfado y el miedo" (Aznar, 2004: 361), recuerda que "Viola también cree que el arte puede tener una 'función curativa'. Dicho con sus propias palabras: que una obra esté en la pantalla puede ser parte del proceso de tu propia vida, puede filtrarse en tu cuerpo. El fundamento de la mayor parte del trabajo de Viola es llevarse a sí mismo y a los otros hacia el autoconocimiento" (2005: 363).

3 "El sentido de la purificación que se opera a partir de la acción de los elementos, y del sufrimiento que comporta, se revela con claridad cuando se conoce la intención manifestada por Bill Viola de complementar esta instalación con otra que se titulará Mary, es decir 'María', la esencia virginal por antonomasia, que culmina y da sentido a la purificación a la que se alude en Martyrs. Respecto a ambas instalaciones Viola ha dicho: 'Los dos temas, Martyrs y Mary simbolizan algunos de los misterios más profundos de la existencia humana, uno de ellos está relacionado con el nacimiento, el otro con la muerte; uno con el consuelo y la creación, el otro con el sufrimiento y el sacrificio. Si logro mi objetivo, las piezas finales funcionarán como objetos estéticos de arte contemporáneo y como objetos prácticos de contemplación y devoción"” (Arola, 2015: s/p).
} 

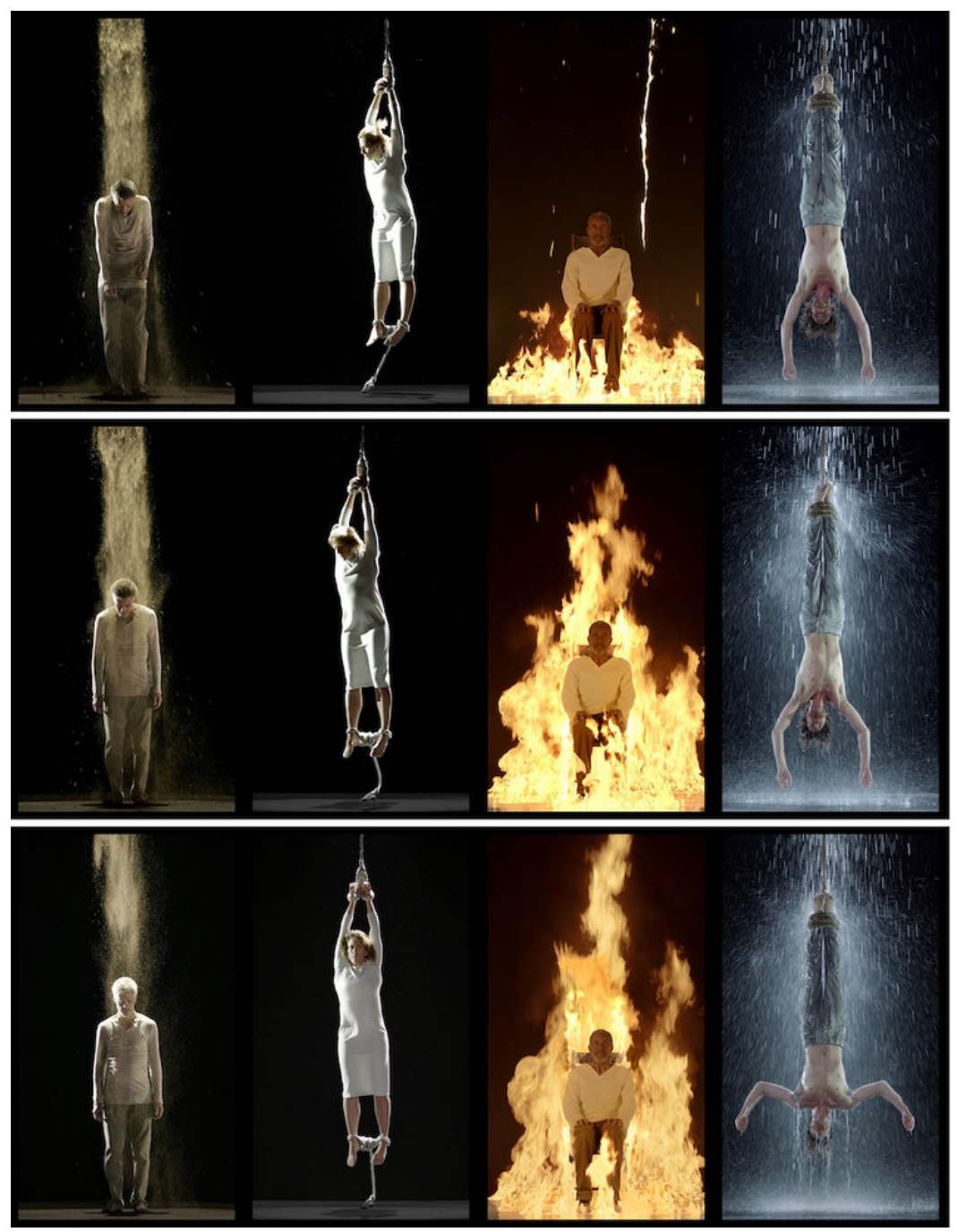

FIGURA 1. BILL VIOLA. MARTYRS. 2014. CATEDRAL DE SAN PABLO (LONDRES)

Como evocaciones que estos mártires son de los cuatro evangelistas y de sus correspondientes manifestaciones elementales -aquí nos permitimos invertir la prevalencia natural de los elementos sobre las diferentes estratificaciones culturales-, representan un muy interesante lazo entre la tradición judeocristiana y su nutriente simbólico ${ }^{4}$-esto es, un cúmulo de cuatriparticiones de rastro milenario de significación, en último término, panenteísta-. El papel de los elementos, en lo que a Occidente se refiere y dentro de unos niveles organizados de simbolización en este caso vinculados con las

\footnotetext{
${ }^{4}$ La obra, según menciona Viola, obedece a un encargo más o menos prefijado: "Hasta mediados del siglo XX hubo en su lugar otras pinturas basadas en María y los mártires. Me insinuaron que no era necesario que fueran estos temas pero, en realidad, lo que estaban haciendo era lanzarme un reto ya que el asunto fundamental de ambos es por qué o por quién estarías dispuesto a dar tu vida. Y ésta es una pregunta demoledora" (Valcárcel, 2016: s/p).
} 
cualidades de los diferentes temperamentos -en línea con la propuesta de Viola, por tanto, lo encontramos desarrollado en los filósofos presocráticos ${ }^{5} \mathrm{y}$, más adelante, en el pirronismo o el estoicismo, entre otros modelos asentados sobre la realidad material de lo existente, además de, por supuesto, en Aristóteles. ${ }^{6}$ Cuanto deseamos exponer es el nexo advertible entre un registro alegórico en este caso cristiano, y unos principios organizativos advertibles en épocas remotas, ${ }^{7}$ así como la consideración de los elementos desde sus propiedades terapéuticas, tal y como se presentan en estratos de nuestra cultura previos a las antropomorfizaciones, ${ }^{8}$ o en momentos en que estas últimas identificaciones obedecen a un deseo más poético que dogmático.

Lo decisivo en lo que nos ocupa es la intención de Viola de engarzar un concreto monoteísmo -dada la ubicación de Martyrs y de Mary, fijado en primer lugar al cristianismo anglicano- no sólo con el resto de monoteísmos sino, lo que parece más revelador, incluso con aquellas manifestaciones sacras previas a la emergencia y consolidación de aquéllos. Desde este lugar, a su vez, y esto adquiere un tono más urgente, es posible vincular estos imaginarios con aquéllos que atraviesan la época actual, y ello incluye, en tanto que formaciones deudoras de las particiones arriba mencionadas, idearios seculares como el ecologismo. ${ }^{9}$ A esta sorprendente relación contribuye el hecho de que tanto María como los mártires se muestren representados como sujetos comunes, seculares. Por todo ello, este arte terapéutico -uno de cuyos fundamentos lo encontramos en el regreso a la comprensión de la naturaleza como physis ${ }^{10}$ y no como instrumento o mero contenedor de materiales para su explotación por parte del individuo- no sólo posee en el trabajo de Viola una vocación ecuménica sino que se pone a su vez al servicio de las necesidades más urgentes del sujeto contemporáneo, quien encuentra en el cuidado del medio -y de sí- una nueva forma de espiritualidad de presupuestos inmanentistas y fundamentos homeostáticos.

Este arte terapéutico o arte del cuidado de sí, no puede dejar de ponerse en relación -precisamente desde el valor purgativo-ascético atesorado por los elementos- con los ejercicios cotidianos y las metas terapéuticas recogidas por Filón en Sobre la vida

\footnotetext{
${ }^{5} \mathrm{Si}$ bien a la hora de vincular el trabajo de Viola es preciso recordar primeramente a Empédocles dada su fundamentación de lo existente sobre los cuatro elementos, de modo análogo, en suma, a la visión privilegiada por el neoyorquino.

${ }^{6}$ Es preciso incidir en el hecho de que desde esta aproximación se alude al contacto de la cultura helénica y prehelénica con esquemas de pensamiento extremo-orientales. Destacable al respecto resulta el contacto de Pirrón con los gimnosofistas. Este concepto de naturaleza que engarza con los principios de la filosofía perenne emerge en la época que corresponde a nuestra Edad Media, con fuerza, en el próximo Oriente, en concreto en la obra de los médicos-filósofos.

${ }^{7}$ Principios organizativos advertibles desde la organización protourbana neolítica conforme a patrones cuaternarios, o desde patrones estilísticos remitentes a la esvástica, figura sobre la que Riegl menciona que "[según A.R. Hein] parece ser inherente a toda una serie de formas ornamentales primitivas muy divulgadas (por ejemplo, la cruz gamada) la tendencia a manifestar el concepto de rotación" (1980: 58).

8 Con la tradicional vinculación de cada uno de los cuatro elementos a diferentes fijaciones conceptualizadas, como observamos en el caso aquí resaltado de los evangelistas.

${ }^{9}$ Noah Harari encuadra preocupaciones como el mencionado ecologismo en el ámbito de las religiones. La argumentación la realiza, fundamentalmente, en su trabajo Sapiens: de animales a dioses.

${ }^{10}$ Volvemos de nuevo a la idea de la naturaleza en los autores presocráticos. Privilegiamos, no obstante, según indicamos, la visión cuatripartita de Empédocles. Sobre el pensamiento del presocrático Aristóteles dirá: "Empédocles supone cuatro (elementos), agregando a la tierra como el cuarto después de los tres mencionados. Y afirma que ellos siempre permanecen y no devienen, salvo en mayor o menor cantidad, uniéndose y separándose en lo Uno a partir de lo Uno." (VV.AA., 2003: 181).
} 
contemplativa, orientados al logro de la salud corporal y -de nuevo desde esta organicidad psicosomática- psíquica (vid. Filón, 2005: 47). Como de habitual en las doctrinas llamadas a sanar el cuerpo por el alma y el alma por el cuerpo, con las que hay que poner en relación las búsquedas de Viola, la contención de las pasiones resulta un aspecto fundamental a la hora de interpretar su creación. Los terapeutas, cabe añadir a lo dicho, vienen a ser comprendidos como bisagra entre una espiritualidad psicosomática oriental y otra occidental participante de un mayor descuido en lo tocante a los ejercicios del cuerpo.

Regresando a los presupuestos homeostáticos que vertebran su trabajo, es preciso recalcar que se trata de un aspecto explorado en las dos composiciones aquí mencionadas, conformadas por imágenes cambiantes con un ritmo casi estático. ${ }^{11}$ La reintegración del arte -en tanto que rito- en el orden natural, y en consecuencia en la función religiosa, hace de estas expresiones objetos revitalizantes en la medida en que integran aspectos existenciales en tantas ocasiones desvinculados y hasta enfrentados. Aquello que el individuo en principio advierte como disgregado queda reincorporado a una unidad sustentante, de manera que las polaridades que anquilosan a la persona son superadas y es entonces cuando resulta posible participar de un proceso de sanación, en línea con la intención señalada de Warburg, por medio de las imágenes. ${ }^{12}$

En consonancia con lo recién expuesto, y puesto que no puede dejarse de lado, como consecuencia de su ubicación permanente, la incidencia teológica -en su sentido restringido- del conjunto, ha de asumirse que el mensaje de estos trabajos favorece el encuentro del culto practicado en la catedral de san Pablo con el conjunto de espiritualidades -entendidas en sentido amplio- que jalonan la contemporaneidad. ${ }^{13} \mathrm{Con}$ ello se logra dotar de maleabilidad a las paredes de la ortodoxia y, en paralelo, desde el

\footnotetext{
${ }^{11}$ Pudiera aplicarse a muchos de los trabajos de Viola el término de "timeless cathedral" que Hanhardt confiere a la serie Martyrs en referencia a lo palpable de un tiempo transmutado en imágenes (2015).

12 Resultan destacables al respecto las siguientes palabras de Didi-Huberman, quien en su trabajo sobre Warburg, y en diálogo con Burckhardt, a quien comienza citando, escribirá: "“somos completamente ignorantes de lo que se llama las fuerzas latentes (latente Kräfte), materiales o morales, del mundo, y no podemos presentir los imprevisibles contagios espirituales que súbitamente pueden transformarlas' [...]. Ahora bien, toda latencia trata de abrirse un retorno a la superficie de los acontecimientos: la 'crisis' (Krise) designaría en Burckhardt esa manera particularmente eficaz que tiene el tiempo de hacer surgir -por contratiempo, por síntoma- su propia potencia" (2009: 99). Líneas adelante Didi-Huberman regresa de nuevo a Burckhardt: “"En historia, la caída va siempre preparada por una desintegración interior, un agotamiento. Una pequeña sacudida exterior basta entonces para hundirlo todo [...]. Una crisis que estalla por un motivo cualquiera se beneficia del impulso general desencadenado por otras numerosas causas; ninguno de los testigos es capaz de discernir cuál será la fuerza que terminará dominando"' (2009: 99-100). Para concluir señalando que "el tiempo libera síntomas y, con ellos, hace actuar a los fantasmas" (2009: 101). La emergencia de imágenes soterradas, en forma a menudo de fantasmas, atesora cualidades terapéuticas -si bien, como todo en unos estratos elementales, en el momento en que no son controladas se advierten potencialmente destructoras-.

${ }^{13}$ Siendo una de ellas, insistimos en ello, el ecologismo, dado el carácter desde el que se refundamenta hoy el término. En estas emergencias éticas o ecológicas, no obstante, se pueden advertir no sólo posos de sacralidad, sino incipientes signos de sentido -más concretamente- trascendental, tal y como acontece en aquellos momentos de la antigüedad en que la naturaleza se entiende como physis y ésta incluso como deidad. Para advertir esta identificación última conviene remontarse, en cualquier caso, a un estrato religioso preindoeuropeo -previo al progresivo proceso de conceptualización abstracta atribuido a estos pueblos-.
} 
vínculo de ésta con espiritualidades emergentes, se pone en relación aquélla con las preocupaciones que estas últimas atesoran, en ocasiones de carácter específico. Este deseo de encuentro, de sello inmanentista pero no ajeno a una raíz metafísica del ser, ${ }^{14}$ queda reforzado por la designación de Mary, a secas, sin alusión al motivo de la virginidad, como título de la obra que complementa a Martyrs. De igual modo, conviene recordar que el deseo de activar procesos sanadores ya sea desde planteamientos colectivos -sacros o profanos-, ya desde experiencias ascéticas de raíz individual y de base temperamental -esto es, regidas por la búsqueda de equilibrio entre los cuatro elementos-, acentúa la idea de organicidad de un conjunto en el que encuentra cabida el espectador que se deja modelar por el objeto estético que tiene ante sus ojos. Seguiremos hablando de ello en el siguiente punto.

\section{ESTÉTICA TEMPERAMENTAL}

Encontramos una muy interesante lectura firmada por Raimon Arola y Lluïsa Vert en relación con el papel de los temperamentos en la obra del neoyorquino. Los autores aluden a "la exposición a los elementos como iniciación como reajuste elemental una vez que el ser transmuta su naturaleza y su inicial proporción de elementos. Esto es, acontece en consecuencia un cambio de humores, temperamental, con todos los rigores que a la persona ello le supone" (2015, s/p). Podrá resultarnos sorprendente la exposición, de modo desinhibido, de principios alusivos a una transmutación o transformación de la estructura anímico-mental del sujeto, proceso acompañado de modificaciones orgánicas desde las que la religión vuelve a emparentarse con una medicina natural tal y como es propuesta desde la filosofía presocrática y, en líneas generales, desde aquellos momentos del saber en que las ideaciones no se presentan desligadas del conocimiento empírico. En este mismo sentido, en referencia directa al trabajo de Viola, leemos líneas adelante:

Las figuras que soportan la acción de los elementos son 'mártires' en el auténtico sentido, pues esta palabra en griego significa 'testigo'; los cuatro personajes conocen experimentalmente el poder de estas fuerzas y, en consecuencia, pueden dar testimonio de ello. [...]

La fuerza de cada elemento es la que provoca un proceso por medio del cual la semilla se pudre y se abre para que pueda surgir el espíritu vegetativo contenido en su interior que dará origen a la nueva planta. Del mismo modo el hombre debe pasar por cada uno de los elementos espirituales para que su vida pura pueda germinar. $[\ldots]$

Se trata de una experiencia que la persona solo puede gestionar desde un lugar interior, pues muestra algo que, aunque provoque sufrimiento, al final se resuelve en un florecimiento. (2015, s/p).

En relación con este recién aludido "espíritu vegetativo", la airosa salida de la prueba ascética quedará en algunos de los trabajos de Viola revelada por la prevalencia del color verde, tal y como se ha ocupado de estudiar Antoni Gonzalo Carbó, quien recuerda al respecto las palabras del videoartista relativas a su deuda con el sufismo y con la simbólica del color -recordemos que Avempace, de honda incidencia en Goethe, tiene precisamente a Aristóteles como uno de sus modelos-: "Jalâl al-Dîn Rûmî [...] es mi fuente suprema de inspiración y a mi entender una de las más grandes figuras literarias y

\footnotetext{
${ }^{14}$ Recordamos que anteriormente hemos hecho referencia al término de panenteísmo para referirnos a una espiritualidad prototípica de nuestra época dentro de la que encuentra acomodo la cosmovisión de Viola.
} 
religiosas de todos los tiempos”. (2004, 52). En este mismo artículo, y en relación con el proceso alquímico experimentado por los personajes, Gonzalo Carbó indica que:

También en la obra de Viola, como en el lenguaje simbólico del Mawlânâ, a la extinción en el fuego (caliente y seco -naturaleza ígnea- = rojo) le sucede la inmersión en el agua (fría y húmeda -naturaleza acuosa- $=$ verde). Una bella video-instalación con audio que expresa esta idea es Five Angels for the Millenium (2001): aquí, simbólicamente, el Ángel de Fuego ('Fire Angel') se sumerge en aguas de color rojo y el ángel del nacimiento ('Birth Angel') sale del agua de color verde (2004: 69).

El autor -cuyos textos conforman un conjunto de valor para quien se interese por la simbólica del color de raíz sufí en la estética reciente- insiste como vemos en la significación del verde, en concreto en el paso del rojo al verde, tránsito encaminado al alcance de la Visio smaragdina: "En la poesía de Rumi, en el camino hacia el misterio divino, el color verde señala el mundo del malakdt, el universo de los ángeles-almas, como el más cercano a nuestro universo cuyo color es la 'luz negra' [...] Residir en la terraza verde es alcanzar el malakdt, es el éxodo fuera del mundo regido por las leyes de la física, la transmutación de los sentidos externos en sentidos espirituales" (2007: 86).

Sin alejarnos de la semántica del color, de la relación natural entre el verde y la vitalidad orgánica, encontramos así mismo en el sustrato mismo del lenguaje, según recuerda André Martinet, una ineludible huella de dicha relación. En su trabajo De las estepas a los océanos. El indoeuropeo y los indoeuropeos, el lingüista recuerda que "La mayor parte de los nombres de color se derivan de los que tienen los objetos caracterizados por el color en cuestión. El verde, por ejemplo, es el color de la vegetación y el inglés green, el alemán grün, no podrán separarse de grow, 'crecer', lo mismo que el lat. uiridis -de donde proceden el fr. vert y el esp. verde- de la raíz documentada en lit. veisti, "propagar"” (1997: 338). La asimilación entre el término que designa la vegetación y el alusivo al crecimiento constituye y determina las permeables redes del lenguaje. Si llevamos este vínculo hacia el ámbito de lo simbólico, podremos comprender que la visualización de la terraza verde supone un hallazgo posterior al padecimiento experimentado por los mártires de Viola, quienes sólo mediante su metafórica exhalación posibilitan su completa transfiguración ontológica. ${ }^{15}$

Este morir para alcanzar el ser lo continúa desarrollando, en el texto arriba recogido, Antoni Gonzalo Carbó. Recogemos por su interés el siguiente pasaje:

En la tradición persa, a la contraposición del par de términos fuego y agua, le corresponde el contraste cromático del rojo del fuego, la sangre y las rosas, símbolo de la combustión interior, y el verde de la vegetación, reminiscencia del Paraíso. [...] Puesto que el fuego es absolutamente opaco cuando es comparado con la verdadera luz, el fuego es la tierra de las tinieblas en la cual uno debe viajar para encontrar el Agua de la Vida, el Aqua permanens, la Fuente de la Vida [...], la fuente verde que se halla en las gargantas más profundas del país de las tinieblas [...] Para poder entrar en el verdor del Más allá, hace falta antes cumplir la invitación que el Profeta lanza en un hadîth incesantemente repetido por todos los sufíes:

\footnotetext{
${ }^{15}$ En su estudio sobre la simbólica de los colores en el misticismo iranio, Corbin ofrece unas pautas en torno a la significación del verde $y$, en lo que afecta a Viola, al papel que desempeñan las figuras angélicas -de fuerte presencia en el estadounidense en recientes trabajos-: “Al término de la vía mística, verás el pozo por debajo de ti. Entonces, el pozo entero se metamorfosea en pozo de luz o de color verde. 'Tinieblas al comienzo, pues era la morada de los demonios, helo aquí ahora radiante de luz verde, pues se ha convertido en el lugar al que descienden los ángeles y la compasión divina"” (Corbin, 2000: 94).
} 
'morid antes de morir' (2004: 69).

La muerte física posibilitada por la experiencia ascética se vincula, en consecuencia, con la idea de un vivir muerto para el mundo -conforme al mensaje paulino-, ${ }^{16}$ con un sobrepasarse a sí mismo a medida que se avanza en el riguroso proceso de ascesis, representado en nuestro modelo por la experiencia de los mártires -y observado (padecido empáticamente) por la figura de María-. La carga significativa asociada a la figura de la maternidad es tal que puede comprenderse que el proceso de engarzamiento de contenidos primordiales -en este caso asentados sobre las figuras de los mártiresqueda apoyado y posibilitado por la fuerza emotiva atesorada por la figura materna, más dada a ser comprendida -dada su elementalidad- como realidad universal, que a fijarse al imaginario de una $\mathrm{u}$ otra cultura. Desde este ángulo, el dolor provocado por el reordenamiento de elementos es presentado como requisito para la regeneración espiritual. Naturalmente, cada uno de estos elementos remite a un cúmulo de motivos pertenecientes a diferentes áreas epistemológicas, no necesariamente presentes en el momento de la concepción del trabajo.

Asistimos, de acuerdo con cuanto vamos exponiendo y desde esta particular reorganización, a una estética heraclítea fundamentada sobre una metamorfosis permanente. La sustitución de una condición ontológica de carácter estático por una entregada a un proceso metafórico confiere a estas creaciones un alto significado en relación con la cosmovisión actual, en tanto que la idea de meta de la historia -no así individual- queda suprimida. En paralelo, o como respuesta a este estado, el sujeto, desprovisto de puntos de referencia fijos, interactúa con la realidad movido -a falta de normas válidas- por motivaciones anímicas o, en rigor, temperamentales. Todo ello encuentra su proyección en las obras ofrecidas por Viola, en las que sus protagonistas se presentan ante nuestra mirada a partir de esquemas arquetípicos y culturales, evidenciando a un tiempo una alta tensión emocional como parte inicial del proceso ascético al que se ven sometidos. La fluctuación de estados resulta, no obstante, válida sólo hasta cierto punto, pues una vez que la videoinstalación llega a su fin - más allá de que sus trabajos se presenten habitualmente en bucle- se advierte que el mundo temperamental que rige las vivencias del sujeto es comprendido meramente como leña prendida con el fin de estabilizar el orden de lo cambiante. La transmutación del individuo queda así consumada.

\section{$3 \operatorname{MARY}(\mathbf{2 0 1 6 )}$}

El papel de esta imagen en la composición de Viola puede ser interpretado sin atención al grupo al que complementa, pero también, natural y preferiblemente, en relación con éste. La tétrada de mártires, desde una interpretación distinta a la ya planteada pero conforme a la que podemos extraer algunas otras pautas hermenéuticas, se presta a revelarse como una representación segmentada en cuatro escenas del

16 "En Martyrs (Earth, Air, Fire, Water), se muestra que la muerte, voluntaria y consciente, es precisamente el paso obligado hacia esta sabiduría" (Arola, 2015: s/p).

En la Epístola a los Romanos, capítulo 6, entre otros muchos pasajes, leemos al respecto: "también vosotros debéis consideraros muertos al pecado y vivos para Dios en Cristo Jesús" [...] "Ofreceos más bien a Dios como si fueseis muertos que han vuelto a la vida” (Biblia de Jerusalén, 2009: 1578). 
padecimiento de Cristo, ${ }^{17}$ figura encarnadora del rito de muerte y renacimiento, en lo que aquí interesa, identificable con todo aquél que simbólicamente toma parte del rito. ${ }^{18} \mathrm{El}$ poder de renovación -destrucción y generación- de agua, tierra, aire y fuego es expuesto desde la violencia ejercida por éstos hacia cada una de las figuras, pero orientado a su vez, conforme a las aportaciones de Gonzalo Carbó o Arola, al reajuste de los cuatro componentes, esto es, a posibilitar la metamorfosis y el renacimiento espiritual. ${ }^{19}$ Prosiguiendo con la fundamentación heraclítea de la estética de Viola, así como con la cualidad terapéutica que concede a sus creaciones, el siguiente pasaje atribuido a Empédocles resulta indicativo de la actividad de las fuerzas elementales actuantes en el sujeto:

Apaciguarás la furia de los infatigables vientos, que sobre la tierra / se agitan y destruyen con sus soplos los campos cultivados. / Y aún, si quieres, dirigirás sus soplos en sentido favorable; / y colocarás después de la lluvia sombría una sequía oportuna / para los hombres, y después de la sequía estival dispondrás / las corrientes que nutren a los árboles y que irrigan el éter, / y retornarás del Hades el vigor de un hombre muerto. (VV.AA., 1979: 141-142).

El pasaje se puede complementar con las palabras que encontramos en la nota al pie de la edición manejada, donde se alude a la comprensión -realizada por E.R. Doddsde Empédocles como figura chamánica. En esta nota se indica que el filósofo de Agrigento "combina las funciones aún indiferenciadas de mago y naturalista, poeta y filósofo, predicador, curador y consejero público. Después de él estas funciones se separaron [...]" (VV.AA., 1979: 141). Sin necesidad de desplazarnos hacia doctrinas si cabe más remotas ${ }^{20}$ con las que hay que poner en relación la tarea de artista, en los cimientos de la cultura occidental -según se ha apuntado al inicio de este trabajoencontramos una concepción homeostática de la naturaleza aún advertible en las doctrinas filosóficas páginas atrás mencionadas -filosofía presocrática en primer lugar $\mathrm{y}$, de forma paulatinamente más racionalizada, aristotelismo, pirronismo y estoicismo, ante todo- que atravesará la filosofía y el misticismo árabe del medievo tal y como hemos indicado a la

\footnotetext{
${ }^{17}$ Por ceñirnos a la ubicación de la obra, aun cuando, evidentemente, su figura nos pone en relación con cualquier otra entidad mítica análoga.

${ }^{18}$ Una sucinta mención paulina (Efesios, 5:14) basta para encuadrar este motivo: "Despierta tú que duermes, y levántate de entre los muertos [...]" (Biblia de Jerusalén, 2009, 1630). La iglesia paulina, iglesia del espíritu, nos sitúa en un dominio de muerte del ser hílico y de elevación pneumática. Cabe indicar que en el momento de la inauguración de Martyrs se leyó un pasaje de la Segunda Carta a los Corintios en el que se contrapone la temporalidad de las cosas vistas con la atemporalidad de lo no perceptible.

${ }^{19}$ Sobre la base de un texto de Corbin relativo a un pasaje de Sohravardî, ofrecemos una nueva perspectiva sobre las imágenes de resurrección de Viola. Si bien no hemos de perder de vista las figuras de los mártires, podemos observar un delicado y poderoso modelo de resurrección en el que, acaso, es el más logrado de sus trabajos: Emergence (2002). Tomando la imagen de la pila bautismal-tumba, es posible a su vez establecer una identificación con la idea del mundo como cripta del que emerge, renovado, el sujeto: "Este mundo visible no es en sí mismo el templo; es la cripta del templo, la cripta cósmica. La iniciación dispensada por el ángel consiste en mostrar al iniciado cómo se sale de la cripta. Para acceder al templo al que el ángel pertenece y al que el iniciado pertenece también por su origen. En la cripta el iniciado no es más que un exiliado. El sentido y la función de los cielos físicos de la astronomía es conducirle a los cielos suprasensibles del mundo espiritual, los del Templo" (Corbin, 2003: 270).

${ }^{20}$ Son numerosas las entrevistas en las que alude a la influencia del budismo zen, el misticismo sufí y el cristiano.
} 
hora de hablar de la simbólica cromática. ${ }^{21}$

Desde el lazo que dos de los fundamentadores de esta simbólica en el mundo árabe, Avempace y Averroes, establecen con el Estagirita, ${ }^{22}$ cabe recoger, por esclarecedora, la siguiente anotación de Victoria Cirlot tomada de su trabajo sobre el Libro de revelaciones de Juliana de Norwich. El pasaje es indicativo del valor atribuido a los elementos como sustancias potencialmente regeneradoras, y sigue a la mención de una descripción del cuerpo realizada por Tertuliano -significativa de su comprensión de la Trinidad- ${ }^{23}$ Menciona Cirlot que "En el sistema aristotélico y para la mayoría de los filósofos medievales, las primeras determinaciones de la materia se sitúan al nivel de los cuatro elementos que la constituyen (tierra, agua, fuego, aire) y de sus cualidades primeras (calor, frío, seco, húmedo). A partir del siglo XIII se retoma esta doble cuatripartición que reposa en gran parte en el tratado De la generación y la corrupción de Aristóteles" (2019: 145-146). Aun teniéndose presente el determinismo resultante de esta concepción material del ser, tiende a dejarse un margen de autodeterminación personal -casi nulo en el estoicismo y de mayor amplitud en Tertuliano-, aspecto que hay que vincular con las posibilidades reorganizadoras -terapéuticas- atesoradas por el individuo, capacidades que no cabe separarlas a su vez de la comprensión al respecto realizada en pleno Renacimiento por Pico della Mirandola -y nos remontamos a este periodo dada la huella que deja sobre la obra de Viola- cuando escribe su Discurso sobre la dignidad del hombre (1486). ${ }^{24} \mathrm{Al}$ respecto cabe recordar que, además de la filosofía antigua, en Pico -como más adelante

${ }^{21} \mathrm{Si}$ bien no podemos recorrer estos caminos, baste con señalar la ya mencionada impronta de Aristóteles sobre Avempace, referente a la hora de abordar la semántica cromática, tal y como explora Henry Corbin en trabajos como Templo y contemplación. Destacamos así mismo el siguiente pasaje de Lapesa alusivo a esta filiación: "El renacimiento europeo del siglo XII y la Escolástica traban conocimiento con Aristóteles, Hipócrates y Dioscórides por medio de Avempace y Averroes, Avicena y los botánicos árabes" (1981: 131). Precisamente en Dioscórides el papel de los elementos desde sus posibilidades terapéuticas se revela fundamental en su comprensión de la medicina.

${ }^{22}$ Cuyos estudios sobre el color y la luz inciden en la teoría cromática de Avempace, según recuerda Corbin (2003: 13).

No obstante, y en contraposición a Averroes, las angelofanías, según dijimos, son constantes en la obra de Viola, que las recupera en nuestra tradición. Corbin se queja de la supresión de estos elementos mediadores por parte de Averroes: "Son estos Ángeles-almas, pobladores de ese mundo intermedio ('âlam al-mithal) en el que tienen lugar las inspiraciones proféticas y las visiones teofánicas, los que serán eliminados por la cosmología de Averroes, eliminación que acarreará consecuencias trascendentales, pues la eliminación de ese ángel 'personal' supone la ruptura de la posibilidad de una comunicación directa de cada ser humano con el Pleroma celestial; a partir de ese momento, será el magisterio o institución eclesial quien pase a monopolizar esa función de mediación." (Sohravardî, 2002: 21-22).

${ }^{23}$ Tras citar el comentario de Tertuliano, señala Victoria Cirlot que: "El pasaje está impregnado de filosofía estoica: desde la idea de que no hay materia que no atestigüe su origen hasta la idea de que todo ser terrestre se compone de los cuatro elementos. El editor de Tertuliano cita las Naturales quaestiones de Séneca como un texto afín a este pasaje." (Cirlot, 2019: 135).

${ }^{24}$ El siguiente texto de Pico ha de contrastarse, sin más, con las breves consideraciones que realizaremos alusivas a las angelofanías: "Las bestias en el momento mismo en que nacen, sacan consigo del vientre materno, como dice Lucilio, todo lo que tendrán después. Los espíritus superiores, desde un principio o poco después, fueron lo que serán eternamente. Al hombre, desde su nacimiento, el padre le confirió gérmenes de toda especie y gérmenes de toda vida. Y según como cada hombre los haya cultivado, madurarán en él y le darán sus frutos. Y si fueran vegetales, será planta; si sensibles, será bestia; si racionales, se elevará a animal celeste; si intelectuales, será ángel o hijo de Dios, y, si no contento con la suerte de ninguna criatura, se repliega en el centro de su unidad, transformando en un espíritu a solas con Dios en la solitaria oscuridad del Padre, él, que fue colocado sobre todas las cosas, las sobrepujará a todas. ¿Quién no admirará a este camaleón nuestro?” (Della Mirandola, 2010: 6). 
en Bruno- hay influencia de Averroes. En cuanto a nuestro objeto de estudio, la posibilidad de renovarse, de 'volverse' a nacer, sobre la que trabaja Viola, emparenta su filosofía estética con aquellos conocimientos perennes recogidos en las distintas tradiciones donde filosofía y medicina convergen. ${ }^{25}$

Por otra parte, regresando a un aspecto ya anticipado, siendo estos mártires una tétrada de figuras cristológicas -tanto si son comprendidas por aislado como desde su integración en una misma realidad óntica-, la presencia de María, equivalente de la Virgen, encuentra parte de su significación en su condición de metafórico marco arquetípico en el que acontece, a modo de retorta alquímica, el proceso que contemplamos en el otro extremo del altar. Pudiera así decirse que en el seno de aquélla se experimenta el sufrimiento que observamos en cada uno de los cuatro mártires, no sólo padecido por éstos o simbólicamente por Cristo -recordemos que no dejamos de estar en un templo cristiano-, sino por todo individuo -ante todo por aquéllos sumidos en un proceso de renovación anímica, nacimiento invertido en la medida en que, lejos de nacerse para el mundo, se muere para él-. Esto en Viola quedará evidenciado en primer lugar en su trabajo Inverted Birth, de 2014 al igual que Martyrs. Nada se pierde en recordar que este renacer del sujeto se expresa de forma patente en los momentos en que un cromatismo verde inunda ocasionalmente la pantalla, según se observa en piezas como la ya señalada por Gonzalo Carbó Five Angels for the Millenium. ${ }^{26}$ Frente a un primer nacimiento fisiológico, este segundo es, en concordancia con el mensaje paulino, de naturaleza espiritual. ${ }^{27}$ Acontecido éste, el sujeto deviene en padre, madre e hijo, a su vez, de sí mismo.

Desde estas visiones arcanas regresamos a las páginas del Libro de revelaciones, en el que encontramos desarrolladas de forma altamente simbólica y desde escenas afines motivos emparentados con la idea de muerte y regeneración. Reiteramos lo ya mencionado en una anterior nota al pie, esto es, el hecho de que la superposición de estratos advertible en los trabajos de Viola nos lleva a comprenderlos a modo de engramas $^{28}$ orientados a exponer las diferentes creencias como reverberaciones de

25 Ambas ciencias han de comprenderse desde su mayor amplitud. Viola es explícito en su posición al respecto: "La naturaleza también me atrae en un sentido espiritual: pretendo ahondar en las leyes intrínsecas del cosmos, en su dimensión trascendente, para entender mejor el hábitat del ser humano." (Porcel, 2009: 257). Esta presentación del cosmos de sentido trascendente parte del organicismo presocrático y aristotélico y se adentra en una sublimación de tono neoplatónico. Judeocristianismo y helenismo se asocian y proponen una reconfiguración de tópicos de hondo sabor gnóstico. La filiación de Viola con la obra de pintores próximos al círculo de Lorenzo de Médici (Botticelli, Signorelli, etc.) apunta a este aludido vínculo como tendencia implícita en su obra. Sobre este motivo se realizó una exposición en el Palacio Strozzi en 2017 con el título "Bill Viola. Rinascimento elettronico". Sus trabajos, en línea con los hallazgos de Warburg, han de comprenderse como dinámicos engramas: la presencia de motivos tradicionalmente asociados al paganismo pervive indisimuladamente en el conjunto de su obra, de modo tal que la pujanza de fuerzas elementales se advierte como fundamento vivo en cada material abordado.

26 "En el corazón del místico opera una verdadera alquimia espiritual que parece estar tipificada por el color rojo del fuego del incendio del alma y el fresco verdor que anuncia la proximidad de la gracia divina" (Gonzalo Carbó, 2007: 82).

${ }^{27}$ Momentos paulinos como el siguiente son explícitos en este sentido: "El primer hombre, salido de la tierra, es terrestre; el segundo, viene del cielo" (1Corintios 15:47: 1606).

28 Todo ello, además, dentro de un manifiesto interés por la memoria cuyo estudio queda fuera de estas líneas. En 1985 creará una obra de resonancias profundas (Giulo Camillo, Bruno, Kircher, Ricci, etc.) ya 
unidades mitológicas. ${ }^{29}$ Resulta esclarecedor al respecto transcribir el siguiente pasaje de la mística inglesa:

Las grandes gotas caían desde la corona como perdigones y parecían salir de sus venas. Cuando salían eran de un rojo pardusco, pues la sangre era muy espesa, y cuando se extendía se volvían de un rojo brillante. Cuando llegaban a las cejas, se desvanecían; y aun así, la sangre siguió corriendo hasta que yo hube visto y comprendido muchas cosas. Sin embargo, la belleza y la vivacidad de su rostro persistían, bello y vivo sin disminución. La abundancia se asemejaba a las gotas de agua que caen de los aleros de una casa después de un fuerte aguacero, cayendo tan copiosa que ningún ingenio humano podría contarlas. Y en su redondez, al derramarse sobre la frente, eran como escamas de arenque (Cirlot, 2019: 59).

La textura de esta sangre, arcillosa y fangosa, evoca aquellas composiciones del neoyorquino en las que la violencia concentra no uno sino varios elementos, como es el caso de la aludida Inverted Birth (2014), en la que la sangre intrauterina baña de nuevo al sujeto para posteriormente quedar reabsorbida hacia lo alto. Asistimos a un sacrificio y a una inmediata revitalización, itinerario que viene a incidir en la prevalencia de un orden metafísico en oposición al puramente fisiológico. El autosacrificio del sujeto deviene en un segundo nacimiento. Inverted Birth guarda parentesco con la explicación que Victoria Cirlot ofrece de la visión de Juliana, quien presenta -y nos recuerda en parte el simbólico sueño de Jung- un caudal de sangre en renovadora circulación. La destacada medievalista indica que "la reconsideración de que la teología del pasaje es paulina (Romanos 5) no resta novedad a la imagen de la sangre descendiendo a los infiernos, inundando la tierra, ascendiendo al cielo y entrando a raudales. Nos introduce en otra dimensión, pues se han operado misteriosas transformaciones del espacio" (2019: 68). Aún en lo referente a este proceso purgativo que en los mártires encuentra su significación completa en la relación establecida con la figura de la maternidad -insistimos en la dualidad establecida entre la expulsión del seno de la madre y el nacimiento a la vida espiritual, así como en la no menos impactante idea de inmersión en el seno materno como lugar de recogimiento frente a un mundo abandonado a su suerte: las interpretaciones son múltiples-, es preciso añadir que Viola va a presentar -no sólo en referencia a Martyrs o a Inverted Birthimplícita y explícitamente esta idea por medio de un primer paso de purificación por fuego, al que sigue uno segundo de ablución por agua, ${ }^{30}$ dando todo ello lugar a una regeneración del individuo. ${ }^{31}$ A partir de la significación que encontramos en ello, y de

desde su título: The Theater of Memory. La emergencia del pasado -renacimiento- a través de imágenes asentadas sobre formas predeterminadas -podría hablarse de arquetípicas- es una constante y acaso la directriz fundamental del trabajo de Viola.

${ }^{29}$ La capacidad visionaria del artista estadounidense le lleva a advertir estratos de significación borrados o difuminados por la superposición de contenidos. Su labor transcultural, su exploración de materiales mitológicos depositados bajo el lenguaje, hace del video una herramienta perfecta: "La imagen digital se ha convertido en la nueva lingua franca" (Porcel, 2009: 257). Viola, añadimos, menciona en sus entrevistas que maneja la cámara como si de un pincel se tratase.

${ }^{30}$ Resulta, en este punto, de interés recordar un pasaje del Sermón LXV de san Agustín por las resonancias que encontramos en las imágenes de Viola: "Conviene que seas cocido por él: como un vaso de arcilla recién hecho, se te pondrá en el horno de fuego, para consolidar la arcilla. El vaso ya cocido por el fuego, no teme el agua. Pero si no fuera solidificado por el fuego, se disolverá en el agua. No te apresures a ir al agua; pasa antes por el fuego, para que atravieses también el agua. De ahí que, en la administración de los sacramentos, durante la catequesis y en los exorcismos, se recurre primero al fuego. De ahí que muchas veces los espíritus inmundos gritan: ¡Ardo, si eso no es fuego! Y luego, tras el fuego del exorcismo, se viene al bautismo, para ir del fuego al agua, y del agua al refrigerio." (Agustín, s/f: s/p).

${ }^{31}$ En referencia al papel jugado por Kira Perov, colaboradora de Viola, y en relación con la expresión de la idea de renovación, resulta orientador el siguiente comentario: "Perov's use of the four elements of earth, air, fire, and water as protagonists helped to resolve the symbolism that was needed to depict 'the darkest 
la fuerza plástica atesorada por las imágenes, comprendemos que los personajes presentados por el videoartista se exponen en un primer momento como animales $\mathrm{u}$ hombres en estado adánico, y que tras un proceso de catarsis -metafórico sacrificio- se ven transustanciados en simbólicos ángeles. Pudiera decirse que estos ángeles, en línea con habituales angelologías, en línea así mismo con las jerarquías celestiales neoplatónicas, no son sino resonancias o emanaciones divinas que emergen y descienden. La propia cualidad de la imagen, virtual, visualizada en pantallas de plasma, implica su imposibilidad de aprehensión. Estamos antes imágenes que simplemente han de ser contempladas: "In the sublime's reemergence in the postmodern world, I shall argue, this very experience of disproportion between the mind's conceptualizing power and an ungraspable complexity, serves as an analogue for or intuition of something else -the infinite, the divine- and thus the promises of trascendence" (Bernier, 2014: 5). Conforme al vínculo trazado, $\mathrm{y}$ al aludido testimonio de Cirlot relativo a su presupuesto paulino, hallamos modelos de esta transmutación ontológica en trabajos como el que nos ocupa, $\mathrm{u}$ otros como los ya señalados Inverted Birth o Five Angels for the Millenium.

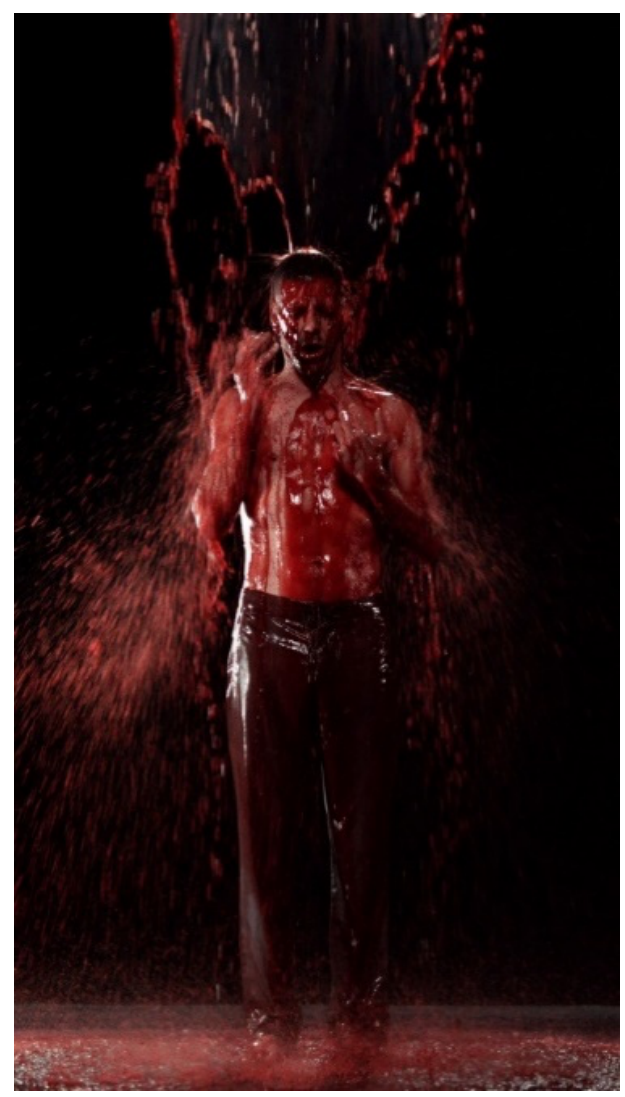

FIGURA 2. BILL VIOLA. 2014. INVERTED BIRTH

hour of the martyr's passage through death into the light'. The use of these elements also serves to create a universal statement of suffering and trascendence that is relevant to all cultures and beliefs" (252). 


\section{PALABRAS FINALES}

La alta carga simbólica -y el concentrado poder, por consiguiente- que en estas composiciones adquieren los elementos, recrea tanto la muerte metafórica del sujeto como su renacimiento espiritual, adquiriendo todo ello, dado el carácter repetitivo de las imágenes, la apariencia de un proceso común -apocatástico, diríamos-. La cronología natural se invierte así mismo o, al menos, encuentra su origen en cada punto de la circunferencia, pudiendo el espectador adentrarse en este círculo y renovarse también él: "El fuego abrasador es agua para el místico que desea la muerte en vida" (2005b: 42). Este místico se presenta en la creación de Bill Viola encarnado en el individuo contemporáneo.

Con la primacía del sujeto secular en la obra del artista -incluso en obras como Martyrs o Mary, según exploramos-, con su privilegiada centralidad, el trabajo del neoyorquino queda relacionado con aspectos actuales y urgentes como lo es, ante todo, la ecología, entendida desde el concepto de cuidado de sí -lo que implica una transformación permanente, la acentuación de un sentido de direccionalidad y metamorfosis en la vivencia del ser- en recíproco vínculo con el cuidado de lo que nos rodea, con aquella realidad con la que entramos en contacto. Si bien no es un aspecto explorado en este trabajo, su peso en la obra de Viola es decisivo y nos acerca estableciendo debidamente un conflicto en el sujeto desde el concepto de catarsis- al pensamiento de Heidegger, donde, insistimos, el cuidado de sí genera comunidad pues implica la atención hacia todas aquellas esferas con las que se relaciona el individuo. Así mismo, el pensamiento de Sloterdijk, a partir del rilkeano 'Has de cambiar tu vida', que propone nuevamente una revolución interior que reordena el exterior, resulta asociable a las búsquedas del videoartista, más si cabe cuando el concepto de técnica se advierte desde su trabajo óptimo para ser refundamentado en tanto que perfila nuevos modelos de convivencia. Estos modelos no sólo articulan la interacción de los individuos, sino que a un tiempo determinan la relación entre éstos y los moldes de existencia de los que cada cual toma parte, moldes conformadores de esferas de ser al tiempo que de reservas de vida en su sentido más pleno. Si bien se trata ésta de una interesante vía de estudio, trasciende de lleno los límites del presente trabajo, conociendo que ahondar en ella nos llevaría decididamente -y esto es aplicable a Mary- al ámbito de la biopolítica, siguiéndose así una cadena que vincularía su obra con las ideas de Kjellén, Foucault, Agamben, o Esposito. Con todo, baste con señalar que la relación entre individuo, esfera comunitaria y esfera natural, perfilada en Mary según se acaba de indicar, nos sitúa de lleno, en este caso, ante la dicotomía zoé / bíos, cuya articulación determina nuestra situación en y ante la realidad.

Más allá de estas vías a explorar, a la hora de cerrar este trabajo nos recluimos de nuevo en las consideraciones desarrolladas. Tras cada uno de los personajes a los que hemos atendido, tras los mártires, María y su hijo, se advierte el arquetipo del que toman parte, remitente en última instancia al principio que rige los distintos elementos. Estos arquetipos sustentantes se presentan a su vez válidos para explorar la experiencia secular del sujeto, así como toda experiencia sacra -común o íntima- cuando permanece arraigada al rito de muerte y regeneración. Con el presente trabajo Viola ahonda en un motivo en 
el que viene indagando desde hace ya cuatro décadas ${ }^{32}$ y que no deja de encontrar motivaciones -aquí no exploradas sino meramente apuntadas- en cuestiones éticosociales, tal y como explícitamente se refleja en Mary. ${ }^{33}$ Todo ello acontece desde un inmanentismo que, lejos de oponerse a una realidad metafísica, la posibilita y determina.

\section{REFERENCIAS}

Agustín de Hipona (s/f). $\quad$ Sermones. En http://www.augustinus.it/spagnolo/esposizioni_salmi/esposizione_salmo_082 testo.htm

[Consultado el 27 de diciembre de 2019].

Arola, R. y Ll. Vert (2015). Bill Viola: contemplación y devoción. Ars Gravis. Arte y simbolismo, s/p. En https://www.arsgravis.com/bill-viola-contemplacion-y-devocion-2/ [Consultado el 27 de diciembre de 2019].

Aznar, Y. (2004). Bill Viola, repertorio de pasiones. Espacio, Tiempo y Forma, Serie VII, Historia del Arte, 17, 355-373.

Bernier, R. R. (2014). The Unspeakable Art of Bill Viola. A Visual Theology. Oregon, USA: Pickwick Publications.

Biblia de Jerusalén (2009). Bilbao: Desclée de Brouwer.

Cirlot, V. (2019). Visión en rojo. Madrid: Siruela.

Corbin, H. (2000). El hombre de luz en el sufismo iranio. Madrid: Siruela.

Corbin, H. (2003). Templo y contemplación. Ensayos sobre el Islam iranio. Madrid: Trotta.

De Alejandría, F. (2005). Los terapeutas. Salamanca: Sígueme.

Della Mirandola, G. P. (2010). Discurso sobre la dignidad del hombre. Revista Digital Universitaria, 11.11, 1-6.

Didi-Huberman, G. (2009). La imagen superviviente. Historia del arte y tiempo de los fantasmas según Aby Warburg. Madrid: Abada.

Gonzalo Carbó, A. (2004). Atravesando el mar de llamas. El sufismo de María Zambrano y Bill Viola. Postdata. Revista de artes, letras y pensamiento, 26, 51-71.

Gonzalo Carbó, A. (2005a). El agua unida a la llama: La extinción en el sufismo de Rumi y en la obra de Bill Viola. Aurora. Papeles del seminario María Zambrano, 9, 37-44.

Gonzalo Carbó, A. (2005b). La extinción como aurora: fuego y agua en el sufismo y en el arte contemporáneo (C. Twombly, W. Laib, B. Viola y S. Neshat). Aurora. Papeles del seminario María Zambrano, 7, 31-43.

Gonzalo Carbó, A. (2007). El viaje espiritual al "espacio verde": el jardín de la visión en el sufismo. Convivium: revista de filosofía, 20, 65-90.

Hanhardt, J. G. (2015). Bill Viola. Malaysia: Thames and Hudson.

Lapesa, R. (1981). Historia de la lengua española. Madrid: Gredos.

Martinet, A. (1997). De las estepas a los océanos. El indoeuropeo y los 'indoeuropeos'. Madrid: Gredos.

Palanco, B. (2014). Entrevista. Bill Viola. 'El misterio es más relevante que la inspiración'. Tendencias del mercado del arte, 71, 30-33.

Porcel, V. (2009). Conversación con Bill Viola. Quaderns de la Mediterrània = Cuadernos del Mediterráneo, 12, 256-257.

Riegl, A, (1980). Problemas de estilo. Fundamentos para una historia de la ornamentación.

${ }^{32}$ Gonzalo Carbó sitúa el inicio explícito de estas búsquedas en una fecha concreta: "A partir del año 1976 [...] manifestó un gran interés por la literatura visionaria y mística" (2005a: 37).

33 Aunque significación metafísica y significación social tienden a aparecer fusionadas en sus composiciones, el autor mencionará: "En mis trabajos utilizo el blanco y el negro cuando quiero hablar directamente al alma, y el color para presentar los aspectos más sociales." (Porcel, 2009: 257). 
Barcelona: Gustavo Gili.

Sohravardî, Sihâboddîn Yahyâ (2002). El encuentro con el ángel. Tres relatos visionarios comentados y anotados por Henry Corbin. Madrid: Trotta.

Valcárcel, M. (2016). Una Virgen de Bill Viola para San Pablo. Alejandra de Argos, s/p. En http://www.alejandradeargos.com/index.php/es/completas/8-arte/41436-una-virgen-de-billviola-para-san-pablo [Consultado el 27 de diciembre de 2019].

VV.AA. (1979). Los filósofos presocráticos II. Madrid: Gredos. 